\title{
Whither the Mathematics/Didactics \\ Interconnection? Evolution \\ and Challenges of a Kaleidoscopic \\ Relationship as Seen from an ICMI \\ Perspective
}

\author{
Bernard R. Hodgson
}

\begin{abstract}
I wish in this lecture to reflect on the links between mathematics and didactics of mathematics, each being considered as a scientific discipline in its own right. Such a discussion extends quite naturally to the professional communities connected to these domains, mathematicians in the first instance and mathematics educators (didacticians) and teachers in the other. The framework I mainly use to support my reflections is that offered by the International Commission on Mathematical Instruction (ICMI), a body established more than a century ago and which has played, and still plays, a crucial role at the interface between mathematics and didactics of mathematics. I also stress the specificity and complementarity of the roles incumbent upon mathematicians and upon didacticians, and discuss possible ways of fostering their collaboration and making it more productive.
\end{abstract}

Keywords Mathematics - Didactics of mathematics - Mathematicians • Mathematics educators · ICMI

\section{Introduction}

I wish in this lecture to reflect on the links between mathematics on the one hand, and the didactics of mathematics on the other, each being considered as a scientific discipline in its own right. From that perspective, mathematics is a domain with a very long history, while didactics of mathematics, or mathematical education as it is predominantly called by Anglophones, is of a much more recent vintage. Such a discussion extends quite naturally to the professional communities connected to these domains, mathematicians in the first instance, and mathematics educators

\footnotetext{
B.R. Hodgson $(\bowtie)$

Département de Mathématiques et de Statistique, Université Laval, Québec, Canada

e-mail: Bernard.Hodgson@mat.ulaval.ca

(C) The Author(s) 2015

S.J. Cho (ed.), The Proceedings of the 12th International Congress

on Mathematical Education, DOI 10.1007/978-3-319-12688-3_7
} 
(didacticians) and teachers in the other. The general framework I mainly use to support my reflections is that offered by the International Commission on Mathematical Instruction (ICMI), a body established more than a century ago and which has played, and still plays, a crucial role at the interface between mathematics and its teaching, between mathematics and didactics of mathematics.

As shown notably by the history of ICMI, there is a long tradition of eminent mathematicians being professionally involved in educational matters, including with regard to primary or secondary education. But the emergence, during the last decades of the previous century, of didactics of mathematics as an internationally recognized academic discipline has had among its effects an increase of the gap between mathematicians and mathematical educators, culturally and otherwise. Both mathematics and didactics depend for their development on research, founded in each case upon specific paradigms eventually hindering the fluidity of the communication between the two groups. While most professional mathematicians are involved not only in the creation or application of mathematics but also in its teaching, only a small number of them actually pay substantial attention to what recent research in education tells about the difficulties intrinsic to the learning of mathematics at various levels. And the development of didactics of mathematics, as a field both of practice and of research with distinctive concepts and vocabulary, amplifies to a certain extent the opaqueness of its results to the outsider. At the same time some suspicion may have developed within the mathematical education community about the role and importance of mathematicians in education. Such a situation may be reinforced at times by somewhat naive views expressed by some mathematicians in educational debates, as well as by the fact that, in opposition to the early days of didactics of mathematics, a larger proportion of didacticians nowadays, including teacher educators, have had little contact with higher mathematics, say, at the graduate level or even at the advanced undergraduate level.

I mainly base my discussion both upon my 11-year experience as ICMI Secretary-General (1999-2009) and on various elements stemming from activities organised by or under the auspices of ICMI, for instance ICME congresses or ICMI Studies, as well as on episodes from its history. I consider different contexts where mathematics and mathematical education interact and the way these contexts have evolved over the years. In connection with the complexity of educational issues related to both the teaching and the learning of mathematics, I also stress the specificity and complementarity of the roles incumbent upon mathematicians and upon mathematical educators, and examine possible ways of fostering their collaboration and making it more productive, notably in the context of ICMI activities.

\section{Linguistic Prolegomena}

Before embarking on my topic per se, it may be helpful to pay attention to some expressions appearing in the title of this lecture, so to make my use of these as clear as possible. 


\section{"Whither" or "Wither"}

In spite of my patronymic, I share with the majority of the people in this audience the fact that English is not my mother tongue. Besides regretting any inconvenience stemming from my "French English", I need to point to potential problems provoked by the use of a certain vocabulary representing not only a substantial elocutionary challenge for non-native English speakers like me, but that moreover is usually not part of daily discourse. Such is possibly the case with the "whither" in my title. I do not know if many of you had to look into a dictionary for its exact meaning. I definitely did, when I first met this interrogative adverb. If my memory serves me well, my first encounter with this intriguing word - or at least the first time it really caught my attention - was in the title of one of the concluding chapters ("Whither mathematics?") of a thought-provoking book by Kline (1980) about the nature and role of mathematics. I met it again many years later through the plenary lecture "Whither mathematics education?" presented by Anna Sierpinska at ICME8, in 1996 (Sierpinska 1998). I remember being fascinated by the idea of the likely future of a given matter being concealed in that single word "whither". And this is precisely what I have in mind in this talk about the mathematics/didactics links.

But depending on one's pronunciation of today's lingua franca, non-trivial difficulties may arise when using this word. You will have noted the two aitches (" $h$ ") in "whither", thus allowing to distinguish (at least visually!) this word from its neighbour "wither", a verb with a totally different meaning. But how is this difference to be communicated orally? I clearly was myself the source of some confusion recently when discussing with a former ICMI officer the topic of the present lecture. Quite obviously I then dropped the first aitch, either inadvertently or by a lack of capacity of rendering it orally in a proper way. "Why are you proposing such a strong title for your talk? was then wondering my colleague. Why do you insist on the possibility that the interconnection between mathematics and didactics may be drying, waning, decaying?" Such is not at all the message I aim at conveying in this lecture, and this is why the initial aitch is so important. As a matter of fact, I am concerned with quite the opposite: how to ensure that this crucial aitch never gets dropped!

\section{Through the Kaleidoscope}

Those of you aware of my long-term involvement in the mathematical preparation of primary school teachers will possibly be familiar with my deep interest for the kaleidoscope, a "philosophical toy" invented — and named 1 —in the early 19th

\footnotetext{
1 The name "kaleidoscope" was coined by Brewster from the Greek words "kalos", beautiful, "eidos", aspect, and "skopein", to see. With a typical poetical flavour, the Chinese name for this instrument, 万花筒 (“wàn huā tŏng”), can be translated literally as ten thousand flowers cylinder,
} 
century by the Scottish physicist Sir David Brewster. ${ }^{2}$ This instrument, so simple yet so fertile, is in my opinion a wonderful "attention-catcher" eventually leading to scientific thinking, as it fascinates people of all ages through the richness and beauty of the images created by the interplay of mirrors. ${ }^{3}$ It is in my opinion an ideal vehicle for putting teachers in contact with geometry, both practical and theoretical. The kaleidoscope has regularly been part of my teaching with primary school teachers for more than three decades (Hodgson 1987), and I still see as an important personal experience for teachers to explore the explosion of images provoked by the actual interaction of physical mirrors, notwithstanding the virtual possibilities offered by the computer (Graf and Hodgson 1990). A thorough theoretical understanding of the mathematical principles underlying the kaleidoscope is a challenge fully appropriate for primary school student teachers, and I am deeply convinced that the mastery of such a mathematical "micro-theory" can have a positive impact on their perception of mathematics and their personal relation to it (Hodgson 2004).

My mention of the kaleidoscope in the context of this talk is more than a mere wink to a mathematical pet subject of mine offering such a fecund pedagogical environment. I use in my title the kaleidoscope as a metaphor in order to suggest the changing nature of the mathematics/didactics relationship, like the stunning, if not unpredictable, alterations provoked on the image generated by a kaleidoscope by even a small shaking of the glass pieces inside the device. The history of ICMI, for instance, vividly illustrates the evolution over the past century of the links between mathematics and didactics, as well as the communities supporting these fields. But more to my point, the complexity and richness of kaleidoscopic rosettes can also serve as an analogy to the potential fruitfulness not only of the connections between mathematics and didactics as scholarly domains, but also of the collaboration between mathematicians and didacticians.

\section{What? - and Who?}

I now wish to comment on the mathematics/didactics tandem on which this talk is based. There is possibly no need to expand on the concept of mathematics in itself,

\footnotetext{
(Footnote 1 continued)

or more appropriately, cylinder with myriads of flowers. In a similar vein, the Korean name, 만화 경 ("mân hwa gyong"), can be translated as ten thousand brightnesses mirrors, again suggesting the proliferation of a myriad of images. Quite interestingly, the word "myriad", used in English to convey the idea of an extremely large number, originally designated a unit of ten thousand in classical Greek numeration.

2 Brewster commented about his instrument that "it was impossible not to perceive that it would prove of the highest service in all the ornamental arts, and would, at the same time, become a popular instrument for the purposes of rational amusement." (Brewster 1819, p. 7).

3 This fascination for the kaleidoscope has possible been rendered no better than by the famous French writer André Gide (1869-1951), 1947 Nobel laureate in literature, in his autobiographical Si le grain ne meurt (cf. Graf and Hodgson 1990, p. 42).
} 
except to stress that I am concerned here with mathematics as both a body of knowledge and an academic discipline implemented as a subject-matter in given teaching and learning environments, at different levels of educational systems all around the world. ${ }^{4}$ The word didactics is slightly more difficult to circumscribe. I have in mind of course didactics of mathematics, rather than a kind of generalpurpose didactics. I am aware that in English the adjective didactic may come with a pejorative connotation, ${ }^{5}$ and that the noun didactics could be interpreted with the somewhat restricted meaning of "the science and art of teaching" - see also Kilpatrick (2003) for similar linguistic comments. Consequently the expression mathematics education has become the one typically used among Anglophone circles to designate the scholarly domain that has developed, especially in the second part of the previous century, in relation to the teaching and learning of mathematics.

It is not my intent to enter here into fine discussions about the respective merits or limitations of expressions such as didactics of mathematics and mathematics education, and to examine their exact scope. Nor do I wish to focus on the specific case of the so-called French school of "didactique des mathématiques"-I refer those interested for instance to the analysis offered by Kilpatrick (2003, 2012). Still I will mostly use here the expression didactics of mathematics (rather than the more frequent mathematics education), partly because of my own linguistic bias, and partly because of a kind of general agreement, especially among some of the European countries, that seems to be emerging about its use, even in English. ${ }^{7}$ In doing so, I am in line with the description proposed by Winsløw (2007), where didactics is understood as "the study of the teaching and learning of specific knowledge, usually within a disciplinary domain" (p. 534). In the same paper, Winsløw stresses how in some European contexts. "[d]idactics is regarded as a continuation of the study of the scientific discipline, in much the same way as the study of its history and philosophy" (p. 524).

\footnotetext{
${ }^{4}$ Dossey (1992) offers an overview of various conceptions of mathematics, including in an historical perspective, and discusses "their current and potential impact on the nature and course of mathematics education" (p. 30). See also Kilpatrick (2008, pp. 29-31), for helpful nuances about the question "What is mathematics?" with regard to educational contexts, in particular in connection with the idea of mathematics then becoming a domain of practice.

5 As is witnessed for instance by the following definition: "in the manner of a teacher, particularly so as to treat someone in a patronizing way", from the New Oxford American Dictionary (2nd edition, 2005, electronic version included in the Mac environment).

${ }^{6}$ According to the Oxford English Dictionary (online version), this seems to be a typical 19thcentury vision. It is in that sense for instance that the word "didactics" is used in the title of one of the sections on the programme of the International Congress of Mathematicians held in Cambridge in 1912 - cf. Hobson and Love (1913), Section IV, Philosophy, History and Didactics.

7 It may be of interest to note that as early as 1968, Hans Georg Steiner was using (in English) the expression "didactics of mathematics" to designate the "new discipline" that, he claimed, had to be established to support what he saw as "new possibilities for mathematics teaching and learning" (cf. Steiner 1968, pp. 425-426). He presented this new discipline as "separate from the "methodology of mathematics teaching"” (p. 426).
} 
Another facet of the mathematics/didactics dichotomy concerns the actors involved in those fields. This is also far from easy to describe, as the context is intrinsically complex and can vary considerably from one country to the other-and even within a single country-, due to economical, social and cultural factors, as well as local traditions. This is why the local educational structures in which these people are to be found (vg, schools, colleges, universities, teacher education institutes, etc., not to speak of research centres and suchlike) come in a variety of forms. That said, I will now try to briefly identify, but without any pretention to exhaustiveness, what may be considered as typical working environments and structural frameworks for the colleagues I have in mind.

One obvious category of actors is that of the mathematicians, that is, people whose main interest is with mathematics as a body of knowledge and eventually contributing to its development through research. ${ }^{8}$ To borrow from the title of a well-known math book from the time of my graduate studies (Mac Lane 1971), they are "working mathematicians", active in the field. The vast majority of these people, and especially those in the academia, will belong to a mathematics unit (department, etc.) and be involved in some form of teaching, from courses to math majors to large classes of engineers or graduate courses and seminars with a handful of students. Because of such teaching duties, they are undoubtedly "educators", although one could think that for a number of them, educational activities do not represent their main professional concern and would even have a possibly limited impact on the evolution of their career (promotion, etc.). Still there seems to be a growing number of faculty members in mathematics department developing a bona fide interest for educational matters, notably at the tertiary level. A crucial issue then becomes how they can find in the community the kind of support needed for their educational endeavour. I shall say a few words about this later.

Among the mathematicians is a subset of specific interest to this talk, and to which I myself belong: those whose teaching is substantially targeted at the mathematical education of teachers, both of primary and of secondary school. I have discussed in (Hodgson 2001) the importance of this specific contribution of mathematicians ${ }^{9}$ - a contribution, I maintain, that should be considered as an intrinsic part of the "mission" of a mathematics department.

But mathematicians are of course not the only players involved in the preparation of mathematics schoolteachers. Another group of teacher educators of prime importance will typically be found in faculties of education (or of educational sciences). While many of them would call themselves mathematics educators, I prefer to use here the expression didacticians, in line with the preceding

\footnotetext{
${ }^{8}$ While I fully adhere with the statement made by IMU president Ingrid Daubechies, in her ICME-12 opening address, that the term "mathematicians" should be construed as including, for instance, participants at an ICME congress, I am using this word, for the purpose of my talk, in a slightly more restrictive (and customary) sense.

9 "Mathematicians have a major and unique role to play in the education of teachers-they are neither the sole nor the main contributors to this complex process, but their participation is essential." (Hodgson 2001, p. 501).
} 
comments. ${ }^{10}$ Besides the graduate supervision of future didacticians or the development of their own research programme, a large portion of the teaching time of didacticians, at the undergraduate level, would mostly be devoted to the education of primary and secondary school teachers. One possible distinction between their contribution to the education of teachers and that of the mathematicians may be the extent to which emphasis is placed on the challenges encountered in the actual teaching and learning of some mathematical topic. This is to be contrasted with the attention mathematicians may give to the mastery of a given mathematical content, both in itself and as a potential piece of mathematics to be taught, as well as its place in the "global mathematical landscape", for instance when seen from an advanced standpoint à la Klein (see Klein 1932).

The actual "location" of didacticians inside the academic environment can vary a lot, but they often belong to a faculty of education. A specific case I wish to stress is when didactics of mathematics is attached, as an academic domain, to the same administrative unit (vg, a given university department) to which mathematics belongs ${ }^{11}$ - a context that may be seen as related to the comments of Winsløw quoted above. Such a situation is far from being the general rule-and I would not want to push it as an ideal universal model-, but it clearly offers an interesting potential for fostering the links between mathematicians and didacticians, and eventually improving mutual understanding and respect.

More generally, there is an obvious need for a community and a forum where mathematicians and didacticians can meet in connection to issues, general or specific, related to the teaching and learning of mathematics. An interesting context to that effect is that offered by ICMI.

\section{A Glimpse into the History of ICMI}

The International Commission on Mathematical Instruction (ICMI) celebrated in 2008 its centennial, an event that stimulated the publication of a number of papers dealing with various aspects of its history. Detailed information about the origins of the Commission and its evolution over the years can be found for instance in Bass (2008b), Furinghetti et al. (2008) and Schubring (2008), three papers appearing in the proceedings of the ICMI centennial symposium. Other papers of a historical nature include Furinghetti (2003) and Schubring (2003), written on the occasion the

\footnotetext{
${ }^{10}$ My reluctance to speak of "mathematics educators" in that context also stems from the fact that in my opinion, expressions such as "mathematics educators" or "teacher educators" should not be construed as belonging exclusively to or denoting specifically either the community of didacticians or that of mathematicians: as stressed earlier, we are all educators, but of course with our own specific ways of addressing educational issues.

11 As a concrete example, I mention that the position in "didactique des mathématiques" created in 1999 at Université Paris Diderot (a scientific university of international research fame) and first occupied by former ICMI president Michèle Artigue is attached to the mathematics department.
} 
centennial of L'Enseignement Mathématique - the journal which since the inception of ICMI has been its official organ-, as well as Hodgson (2009). The survey of Howson (1984) was prepared on the occasion of the 75th anniversary of ICMI. Many ICMI-related sections are found in Lehto (1998), a book about the history of the International Mathematical Union (IMU), the organization to which ICMI owes its legal existence.

The beginnings of ICMI can be seen as resting upon the assumption that mathematicians have a role to play in issues related to school mathematics - at least at the secondary level. Its establishment resulted from a resolution adopted at the Fourth International Congress of Mathematicians held in Rome in 1908 and appointing a commission, under the presidency of the eminent German mathematician Felix Klein, with the mandate of instigating "a comparative study of the methods and plans of teaching mathematics at secondary schools" (Lehto 1998, p. 13). This resolution can be seen as addressing concerns present at the turn of the twentieth century in educational debates and provoked by the spreading of mass education combined with a greater sensitivity towards internationalism that stimulated the need for self-reflection, comparison and communication. Still today, the formal definition of ICMI's global mission and framework for action points to the importance of connecting its educational enterprises with the community of mathematicians as represented by IMU. For instance the Terms of reference of ICMI state that "ICMI shall be charged with the conduct of the activities of IMU bearing on mathematical or scientific education". More details are provided below on the recent and current links between ICMI and IMU.

A sharp distinction is manifest between the "old ICMI's tradition" (Furinghetti 2008 , p. 49) of publishing national reports and international analyses of school curricula, as done abundantly in its early years, ${ }^{12}$ and the activities of ICMI after its rebirth $^{13}$ in 1952 , at a time when the international mathematical community was being reorganized, as a permanent commission of the then newly established IMU. Furinghetti (2008) stresses how at that latter time "the developments of society and schools were making the mere study and comparison of curricula and programs (...) inadequate to face the complexity of the educational problems" (p. 49). Highlighting the use of the "new expression 'didactical research"" in the title of a short lecture presented at the 1954 International Congress of Mathematicians, she presents this as a sign of an emerging shift about mathematics education, from a "national business" mainly concerned with curricular comparisons to a "personal business" centred on learners and teachers (Furinghetti 2008, pp. 49-50). The 1950s also saw the development of a new community, the Commission Internationale pour l'Étude et l'Amélioration de l'Enseignement des Mathématiques

12 Fehr (1920-1921, p. 339) indicated for instance that between 1908 and 1920, ICMI, jointly with eighteen of the countries it gathered, had produced 187 volumes containing 310 reports, for a total of 13,565 pages.

13 This rebirth followed a hiatus in ICMI activities around the two World Wars. Like most international scientific organizations of that time, ICMI was deeply affected by the ongoing international tensions. 
(CIEAEM /International Commission for the Study and Improvement of Mathematics Teaching, ICSIMT), where the importance of reflecting on the students themselves as well as on the teaching processes and classroom interactions was strongly emphasised, in contrast to educational work typical of the time.

Such deep changes were the reflection of the emergence of a new sensitivity with regard to educational issues. As a result, a context arose propitious not only to the development of new approaches to study the teaching and learning of mathematics, but also to the eventual birth of a new academic discipline, gradually accepted and recognized as such, namely didactics of mathematics (i.e., mathematics education in usual parlance). ICMI itself was at times strongly influenced by these changesFuringhetti et al. (2008) speak of a "Renaissance" of ICMI under the influence of events from the 1950s and 1960s. But ICMI also accompanied the evolution of didactics of mathematics, and at times even fostered it, thus contributing significantly to its acceptance as a bona fide academic domain.

This was particularly true during the ICMI presidency of Hans Freudenthal from 1967 to 1970 . This particular moment was definitely a turning point in the renewal of ICMI, principally because of two major events that then occurred, essentially at Freudenthal's personal initiative, and that proved to have a considerable long-term impact: the establishment in 1968 of an international research journal in didactics of mathematics (Educational Studies in Mathematics, ESM), and the launching in 1969 of a new series of international congresses (the International Congress on Mathematical Education, ICME), the twelfth of which we are now celebrating in Seoul.

Bass (2008b) uses the expressions "Klein era" and "Freudenthal era" (from the names of the first and eighth presidents of ICMI) to designate two pivotal segments structuring the life of ICMI up to its 100th anniversary and corresponding more or less to its first two half-centuries: from ICMI beginnings in 1908 up to World War II, and from ICMI rebirth in 1952 to its centennial celebration. Of central interest to my lecture is the distinction Bass introduces about the actors then involved in ICMI circles. While those of the first period were mostly "mathematicians with a substantial, but peripheral interest in education, of whom Felix Klein was by far the most notable example, plus some secondary teachers of high mathematical culture" (Bass 2008b, p. 9), the majority of the players in the Freudenthal era are professional researchers in the teaching and learning of mathematics, i.e., didacticians. Bass also adds that "[i]n this period we see also the first significant examples of research mathematicians becoming professionally engaged with mathematics education even at the scholarly level" (Bass 2008b, p. 10), and suggests Freudenthal as a outstanding example of such a phenomenon - but of course the name of Hyman Bass himself provides an eloquent example of a more recent nature. A thorny question, in that connection, is the extent to which the growing specificity of the main actors of the Freudenthal era may create a widening distance with the "working mathematician" with regard to educational issues.

As discussed in Hodgson (2009), the presidency of Freudenthal resulted in what might be rightly seen as "years of abundance" for ICMI, in the sense that the scope and impact of its actions expanded considerably. Not only were the newly established ESM and ICMEs highly successful, but also new elements were gradually 
added to the mission of ICMI. To name a few, ICMI introduced in the mid-1970s a notion of Affiliated Study Groups, serving specific segments of a community becoming more and more diverse. ${ }^{14}$ There was also a regular collaboration between ICMI and UNESCO, contributing in particular to outreach actions of ICMI towards developing countries. And later, in the mid-1980s, the very successful program of ICMI Studies was initiated. Still this deep evolution of ICMI, notably through the influence of Freudenthal himself, did not happen without some tensions with IMU, in particular as it was often the case that IMU faced decisions that were faits accomplis, taken without any consultation between the Executive Committees of ICMI and IMU - such had been the case for instance with the launching of the first ICME congress. ${ }^{15}$

Another moment of tension between IMU and ICMI happened in connection with the program of the section on the Teaching and Popularisation of mathematics at the 1998 International Congress of Mathematicians. ${ }^{16}$ As a consequence, the first Executive Committee of ICMI on which I served, under the presidency of Hyman Bass, had to deal with an episode of misunderstanding, and even mistrust, between the communities of mathematicians and didacticians as represented by IMU and ICMI. I will come back to this episode later in this lecture and contrast it with the very positive climate of collaboration and mutual respect between these two bodies that now prevails.

This overview of the history of ICMI may help appreciate the origins of didactics of mathematics as an academic domain, as well as its evolution over the years. One can also see the changing profile of both the main actors involved in the reflections about the teaching and learning of mathematics and the communities gathering them, notably via the two main bodies under consideration in the context I am discussing, ICMI and IMU.

${ }^{14}$ HPM and PME, the first two Study Groups affiliated to ICMI, both in 1976, are typical of the development of several specific strands in didactics of mathematics that has happened during the last 35 years or so. The affiliation in 1994 of WFNMC, whose action is centered on mathematical competitions, is linked to an interest of a number of mathematicians concerning the identification and nurturing of mathematical talents. In their survey of international organizations in mathematics education, Hodgson et al. (2013) contrast the mere three international bodies established up to the early 1960s (ICMI - 1908, CIEAEM-1950 and CIAEM - 1961) with the proliferation since the mid-1970s, each new body corresponding to a particular component of the mathematics education landscape. They comment that "[t]he presence of such subcommunities wanting to become institutionalized within the mathematical education world can be interpreted as a sign of the vitality of the field and the diversity of its global community" (p. 935).

15 The interested reader will find in Lehto (1998) and Hodgson (2009) more information about this episode of tension between IMU and ICMI resulting from Freudenthal's initiatives.

${ }^{16}$ Comments on this episode and its context, notably with respect to the so-called 'Math War' in the USA, can be found in Artigue (2008, p. 189). See also Hodgson (2009, pp. 85-86), and in particular endnote 5, p. 94. 


\section{Some Challenges that Mathematicians and Didacticians Are Facing}

I commented above on the fact that both mathematicians and didacticians have a specific contribution to bring to educational issues, and in particular to the preparation of mathematical schoolteachers. In a sense they are more or less compelled to collaborate - at least in principle. But that is easier said than done.

One point at stake, in the case of mathematicians, is the extent to which they are willing to fully acknowledge education as part of their real responsibilities. But there are encouraging signs on that account. For instance more and more national societies of mathematicians, most of which are typically centred on research in mathematics, now devote a non-negligible part of their energy and activities to educational issues, very often with a genuine concern. A striking example, to take one close to my personal environment, is given by the American Mathematical Society, definitely an outstanding research-supporting body, but with pertinent and well-focused actions about educational matters. In a similar vein, one could think of the European Mathematical Society, whose Education Committee has launched in 2011 a series of articles in the Newsletter of the EMS under the general label 'Solid findings' in mathematics education. The 'solid findings' papers are designed as "brief syntheses of research on topics of international importance" (Education Committee of the EMS, 2011 p. 47) which aim at presenting to an audience of nonspecialists (especially mathematicians and mathematics teachers) what current research may tell us about how to improve the teaching and learning of a given mathematical topic. The message conveyed by such societies is very clear concerning the place that mathematicians may or should occupy with regard to educational matters, and even debates. ${ }^{17}$ The message is also clear, consequently, about the responsibilities of a math department in this connection with respect to the inclusion of education as part of its mission. But transferring this into the daily life of the department is far from trivial.

17 In his ICME-10 plenary lecture concerning the educational involvement of mathematicians, Bass (2008a) makes an important caveat:

I choose specifically to focus on the involvement of research mathematicians, in part to dispel two common myths. First, it is a common belief among mathematicians that attention to education is a kind of pasturage for mathematicians in scientific decline. My examples include scholars of substantial stature in our profession, and in highly productive stages of their mathematical careers. Second, many educators have questioned the relevance of contributions made by research mathematicians, whose experience and knowledge is so remote from the concerns and realities of school mathematics education. I will argue that the knowledge, practices, and habits of mind, of research mathematicians are not only relevant to school mathematics education, but that this mathematical sensibility and perspective is essential for maintaining the mathematical balance and integrity of the educational processin curriculum development, teacher education, assessment, etc. (pp. 42-43). 
I dream of a day when it would be normal for a university math department to open a tenure-track position in mathematics but with a very strong educational emphasis, vg with regard to the preparation of schoolteachers or the development of innovative teaching approaches for very large undergraduate classes. Some of this already exists in some places, ${ }^{18}$ but at a much too modest level altogether.

But an immediate concern follows: what about promotion to a higher academic rank? Would a significant involvement in education by a mathematician be judged by his peers as a valuable academic activity, on a par, say, with mathematical research or supervising graduate students? Many indicators point to the fact that this may remain for some time a major challenge that university administrations will be facing. But there are signs that mentalities may be changing. ${ }^{19}$ Still it would probably be naive to expect a young mathematician recently hired by a math department to devote much time and energy to education matters, unless the position occupied would be very explicit on that account.

In a survey of the ICMI program of actions as seen from a Canadian perspective that I presented at a meeting of the Canadian Mathematics Education Study Group (Hodgson 2011), I suggested as a major challenge for the Canadian community the question of the actual involvement of individual mathematicians-especially the young ones - in educational matters and in activities of a group such as CMESG. The same challenge also exists, at the international level, with regard to the participation of mathematicians in activities of ICMI. What percentage of the people in the present audience, for instance, would consider themselves first and foremost as "working mathematicians"?

That said, past implications of mathematicians in educational matters have not been always optimal, to say the least. The level of rigor typically shown by mathematicians in their own research work is sometimes less perceptible when they come to express opinions about educational matters, sometimes on the basis of extremely naive observations or opinions. Bass and Hodgson (2004) comment for instance that "mathematicians sometimes lack a sufficient knowledge and/or appreciation of the complex nature of the problems in mathematics education" (p. 640). A particularly eloquent episode on that account is probably that of the Math War. ${ }^{20}$ In her presidential closing talk at the ICMI Centennial symposium, Artigue (2008) describes not only the role of ICMI at the interface of mathematics and mathematics education, as announced in the title of her paper, but also at the interface of the communities of mathematicians and didacticians. She speaks of the

\footnotetext{
18 As a concrete example, the mathematics department to which I belong has currently two such positions for mathematicians, one established as early as in the mid-1970s for the mathematical education of primary school teachers, and the other (mid-1990s) for secondary teachers.

19 I have witnessed, over the past decade or so, a few successful cases of promotion for tenure or for full professorship concerning mathematicians with a career strongly focused on education and belonging to renowned research-oriented math departments.

${ }^{20}$ Bass (2008a) notes about the expression "Math War" that it is "an unfortunate term coined in the U.S. to describe the conflicts between mathematicians and educators over the content, goals, and pedagogy of the curriculum" (p. 42).
} 
tensions that arose in the 1990s between those communities because "the supposed influence of mathematics educators was considered by some mathematicians as an important, if not the major, source of the observed difficulties in mathematics education, leading to such extremes as the so-called Math War in the USA" (p. 189).

Such a perception by mathematicians connects to a comment from Winsløw (2007), when he contrasts the necessary close ties he sees didactics having with the discipline, and the reality of the "[i]nstitutional policies and tradition" that imposes a distance between mathematicians and didactics (p. 533). He adds that "[t]he hesitancy of mathematicians to admit the need or worth of didactics could perhaps also be interpreted as an instance of a more general scepticism, among mathematicians, with respect to educational research." (p. 534)

But another side of the coin is related to the fact that didactics of mathematics has grown over the past decades into a fully-fledged academic domain, so that it has developed its specific paradigms, concepts, vocabulary. An unavoidable and obvious consequence is an increase of the communication gap between mathematicians and didacticians. Issues connected to the teaching and learning of mathematics can no more be approached with mere naive views or ideas-fortunately, one may say! But even mathematicians with a genuine interest in education feel a greater distance, as communication has become less transparent. A body of knowledge has now been developed, which must be grasped to a certain extent by mathematicians wishing to be part of the ongoing reflections. ${ }^{21}$ Mathematicians will of course be familiar with this phenomenon internally, from one branch of mathematics to the other, but they may not be sensitive to its importance when it comes to educational contexts, if they have somehow developed the conviction that educational matters could be addressed seriously even through a very rudimentary approach. There is a responsibility for mathematicians here to keep abreast of recent didactical developments. But maybe more to my point, there is a responsibility for didacticians to make their work accessible without imposing unnecessary jargon or constructs. I believe more needs to be done on that account.

I would like to conclude this part of my talk with a comment of a possibly sensitive nature concerning the education of didacticians and the prerequisites they

21 It is of interest to note, in that connection, that without denying the importance for mathematicians of gaining competency with respect to current developments in didactical research, some networks are developing that allow mathematicians to discuss educational issues and develop familiarity with ongoing work in less 'threatening' contexts, so to say. Such is the case for instance of Delta, an informal collaboration network among Southern Hemisphere countries that has developed since the end of the 1990s. In their survey of international organizations in mathematics education, Hodgson et al. (2013) write: "A central idea of Delta is to provide a forum in which mathematicians feel comfortable in discussing issues related to tertiary mathematics teaching and learning without being intimidated by what some may consider educational jargon or constructs. Many participants at the conferences are thus mathematicians wishing to report about a teaching experience or experiment that would normally not classify as bona fide research in mathematics education, but may still be helpful in inspiring those who want to reflect on their teaching" (p. 927). 
should meet to be recognized as such. To make my case clear, I have in mind here the mathematical prerequisites. This issue is even more difficult to circumscribe as it does vary considerably from one country to the next.

As a starting vantage point, let me stress that the majority of the didacticians of my generation, if not all, had a substantial education in mathematics before switching to didactics of mathematics. The reason is simply that graduate studies in mathematics education are still, in most places, of a somewhat recent vintage. So it would not be so uncommon for a didactician of my age to have first done a certain amount of studies in mathematics, even at the graduate level. Today, with the development of didactics of mathematics as an autonomous academic field, the situation has changed substantially. While in many countries the road to didactics of mathematics is still intertwined with an important mathematical component, often of an advanced nature, I am aware of contexts where such is not the case, contexts where someone could be called a didactician of mathematics while having a rather limited experience of undergraduate mathematics, if any, even of the level of basic calculus or linear algebra. I must say that I really see problems with such a possibility. I do not wish here, of course, to express any opinion that may be received as offensive or as a personal criticism by any individual. It is more the "system" allowing this to happen that I want to comment on.

A didactician with no personal direct experience of mathematics at a somewhat advanced level will in my opinion lack a global "vision of the mathematical landscape" that I see as crucial, some aspects of it will escape his or her expertise. I am not at all suggesting here that all didacticians of mathematics should have followed loads of graduate math courses or experienced highly specialized mathematics research. But to take a concrete example, a deep understanding of basic number systems is clearly facilitated when these are considered as steps on the road towards the real numbers, the basic context for elementary analysis.

The present context does not allow me here to enter into fine discussions about the mathematical background that I would hope didacticians to have experienced. In a certain way, as may be the case with the mathematical education of teachers, rather than a simple matter of "doing more math", it is a matter of doing more math that may prove to be significant in order to allow the development of a deep intuition of the mathematical objects one is bound to meet in didactical situations.

Paying attention to this aspect is clearly a good way of facilitating communication between mathematicians and didacticians, as well as helping to foster mutual respect and understanding, unquestionably a vital ingredient in my opinion.

\section{ICMI at the Dawn of Its Second Century}

In this final section I examine selected actions recently launched by ICMI that may offer ways of fostering the collaboration between mathematicians and didacticians, and making it more productive. I am not proposing these undertakings as representing a kind of "ideal future" for mathematics or for didactics, nor for their 
interconnection. But these may be considered as pointing to possible models for concrete joint efforts bringing together the two communities discussed in this paper.

A common feature of the three projects that I discuss below is that they have been launched jointly by ICMI and its mother organization IMU. They thus represent meeting grounds for mathematicians and didacticians as they are represented by these two bodies. It is appropriate from that perspective to go back to the time of the beginnings of the term of office of the first ICMI Executive Committee under the presidency of Hyman Bass. I have already alluded earlier in this paper to two previous events that had provoked not only tensions between ICMI and IMU as bodies, but also between the two communities of mathematicians and didacticians: the so-called Math War in the USA and the turmoil resulting from the setting up of the program of the section on Teaching and Popularization of mathematics at the 1998 ICM. To use the words of Artigue (2008) in her description of the resulting context, "tension was at its maximum" (p. 189). She also comments that when the 1999-2002 ICMI Executive started its term of office, the situation had evolved so badly that "[v]oices asking ICMI to take its independence from a mother institution that expressed such mistrust were becoming stronger and stronger" (p. 189). But she finally concludes:

Retrospectively this crisis was beneficial. It obliged the ICMI EC to deeply reflect about the nature of ICMI and what we wanted ICMI to be. This led us to reaffirm the strength of the epistemological links between mathematics and mathematics education (...). At the same time, we were convinced that making these links productive needed combined efforts from IMU and ICMI; the relationships could not stay as they were. (p. 190)

Conscious and explicit efforts were thus made by the IMU and ICMI Executives to improve the situation. I have described in Hodgson $(2008,2009)$ some of these efforts, which started with the (re)establishment of regular contacts between the two ECs, and especially between the presidents and secretaries [-general], and eventually resulted in the mounting of joint IMU/ICMI projects. Consequently, "after certain periods of dormancy and at times profound distance" (Hodgson 2008, p. 200), the IMU/ICMI relations were entering a time of welcomed harmony and intense collaboration. Concrete examples of such collaboration are given in Hodgson (2009, p. 87).

It should be mentioned, en passant, that a stunning outcome of this reinvigorated relationship, totally unexpected at the time of the 1998 crisis, is the "dramatic and historic change in the governance of ICMI" (Hodgson 2009, p. 87) represented by the fact that since 2008, the election of its Executive occurs at its own General Assembly (such as the one held just prior to this congress), rather than at the IMU GA, as was the case earlier. Such a development is a strong evidence of the maturity not only of the field represented by ICMI, but also of the relationship of ICMI with the organization to which it owes its legal existence. ${ }^{22}$ More comments on this quite extraordinary episode can be found in Hodgson (2009).

22 In that connection, the following comment made by IMU President László Lovász in his report to the 2010 IMU General Assembly may be of interest: "The IMU has a Commission, the ICMI, to 
I now describe briefly three recent projects organized jointly by ICMI and IMU. I believe these suggest that concrete actions bringing together mathematicians and didacticians may contribute to resolve the issue of the mathematics/didactics interconnection. Additional information on these projects is to be found on the ICMI website.

\section{The "Pipeline" Issue}

Already in 2004, IMU approached ICMI, its education commission, expressing concerns in connection with a perceived decline in the numbers and quality of students choosing to pursue mathematics study at the university level and requesting the collaboration of ICMI to better understand this situation. The ensuing discussions pointed to another related phenomenon that needed to be investigated, namely the apparently inadequate supply of mathematically qualified students choosing to become mathematics teachers in the schools. IMU invited ICMI to partner in this undertaking, and take responsibility for its design.

Eventually the project (coined "Pipeline") was connected to, and became an extension of, the work of one of the Survey Teams for ICME-11, on the topic of "Recruitment, entrance and retention of students to university mathematical studies in different countries". It aimed at gathering data about different countries as well as promoting better understanding of the situation internationally. It was decided to focus on eight pilot countries for reasons of manageability (Australia, Finland, France, Korea, New Zealand, Portugal, UK, and USA), and to centre the study around four crucial transition points:

- From school to undergraduate program

- From undergraduate program to teacher education (and to school teaching)

- From undergraduate program to higher degrees in mathematics

- From higher degrees to the workforce

The final report of the Pipeline project was presented in a panel at the last International Congress of Mathematicians held in 2010 in Hyderabad, India. The resulting picture ${ }^{23}$ is that there may not be a worldwide crisis in the numbers of mathematically gifted students, but that there is a crisis in some of the pilot countries. The numbers of such students in universities is susceptible to changes in school curricula and examination systems.

\footnotetext{
(Footnote 22 continued)

deal with math education. The [IMU] General Assembly in 2006 gave a larger degree of autonomy to this Commission, including separate elections for their officials. I would say that this did not loosen the connections between IMU and ICMI, to the contrary, I feel that we have developed an excellent working relationship.” (Lovász 2010, p. 13).

${ }^{23}$ From ICMI quadrennial report of activities 2006-2009 submitted to the 2010 IMU General Assembly [cf. Bulletin of the International Mathematical Union 58 (2010, p. 100)].
} 


\section{ICMI from Klein to Klein}

It was at the first meeting of the 2007-2009 ICMI Executive Committee, under the presidency of Michèle Artigue, and in the context of a discussion about worthy projects that would bind the communities of mathematicians and didacticians, that the so-called Klein project was first mentioned. The ICMI EC saw it as a valuable undertaking to revisit the vision of ICMI first President, Felix Klein, in his milestone book Elementary mathematics from an advanced standpoint, published a century earlier and based on his lectures to secondary teachers. Klein's aim was on the one hand to help prospective and new teachers connect their university mathematics education with school mathematics and thus overcome the "double discontinuity" which they face when going from secondary school to university, and then back to school as a teacher (cf. Klein 1932, p. 1). But more generally Klein wanted to allow mathematics teachers to better appreciate the recent evolution in mathematics itself and make connections between the school mathematics curricula and research mathematics. This is in line with the view that a fundamental contribution of mathematicians to the reflections on teaching is by providing teachers with access to recent advances in mathematics and to conceptual clarifications (cf. Artigue 2010).

The reflections of the ICMI EC on this project were pursued in conjunction with the IMU EC and a Design Team responsible for the project was jointly appointed in 2008. The Klein project has already provoked a lot of very positive reactions from mathematicians, didacticians and teachers, and it is expected to have a triple output: a book simultaneously published in several languages, a resource DVD for teachers, and a wiki-based web-site continually updated and intended as a vehicle for the people who may wish to contribute to the project in an ongoing way. ${ }^{24}$

\section{Capacity and Networking}

The history of ICMI shows a long tradition of outreach initiatives with regard to developing countries. But this prime responsibility of our community has received a renewed attention recently. In her reviews of challenges now facing ICMI, Artigue (2008) stresses the importance, for the successful integration of colleagues from developing countries into the ICMI network, of developing new relationships between "centers and peripheries". She thus points to a necessary evolution from the traditional "North-South" model towards "more balanced views and relationships" (Artigue 2008, p. 195).

The Capacity and Networking Project (CANP) was developed by ICMI with this spirit in mind. It aims at enhancing mathematics education at all levels in developing countries by supporting the educational capacity of those responsible for the

${ }^{24}$ More information on the project and its evolution can be found at www.kleinproject.org. 
preparation of mathematics teachers, and creating sustained and effective networks of teachers, mathematics educators and mathematicians in a given region. CANP was officially launched in 2011 jointly by IMU and ICMI, in conjunction with UNESCO. A prerequisite for the acceptability of a given proposal is some evidence of existing collaboration between local mathematicians and mathematics educators.

Each CANP program is based on a two-week workshop of about forty participants, half from the host country and half from regional neighbours. It is primarily aimed at mathematics teacher educators, but also includes mathematicians, researchers, policy-makers, and key teachers. Three CANP actions have already taken place or been announced: Mali (2011), Costa Rica (2012) and Cambodia (2013).

\section{Conclusion}

This lecture has centred on the specificity and complementarity of the contributions brought by mathematicians and didacticians of mathematics to the reflections on the teaching and learning of mathematics. Another more encompassing approach would be to consider the general framework of the sciences to which research in the didactics of mathematics is connected because of its interdisciplinary nature. The importance of "defining and strengthening the relations to the supporting sciences" is discussed in Blomhøj (2008), where emphasis is placed on the need for mathematics education research "to benefit from new developments in the supporting disciplines" (p. 173). In particular the author stresses that "[o]n a more political level the relationships to the supporting disciplines are very important for the integration of mathematics education research in academia and thereby for the institutionalisation of our research field" (Blomhøj 2008, p. 173). Mathematics appears of course as a fundamental cas de figure on that account.

The issue of the mathematics/didactics interconnection is clearly a very vast one and my focus in this talk was to look at it from the vantage point of the International Commission on Mathematical Instruction, through both its history and its current actions. In a survey paper aiming at encouraging mathematicians' participation to the ICME-10 congress, Bass and Hodgson (2004) have raised the question: "So how are mathematics and mathematics education, as domains of knowledge and as communities of practice, now linked, and what could be the most natural and productive kinds of connections?" Their comment was that "ICMI represents one historical, and still evolving, response to those questions at the international level" (p. 640). To borrow from the beautiful title of Artigue (2008), ICMI was, and is still there, at the interface between mathematics and mathematics education.

In his reaction to Kilpatrick's paper (2008) on the development of mathematics education as an academic field, Dorier (2008) mentions the multiple types of cooperation that mathematics education has developed with other academic fields "because the development of research shows that the complexity of the reality of education needs to be tackled from different viewpoints" (p. 45). Emphasizing the 
importance for mathematics education, amidst this diversity, "to put forward the specificities of its objects, methods, and epistemology" (p. 45) in comparison to other fields connected to educational issues, he notes the following:

In that sense, the relation [of mathematics education] to mathematics is essential, and the role of ICMI is thus vital in order to maintain and develop in all its variety an academic field specific to mathematics education that maintains a privileged relation with the mathematical community at large. (p. 45)

But seeing as a risk that mathematics education may fail to develop as a fullyfledged autonomous academic domain and be absorbed in related fields, Dorier concludes that "[a] barrier against this possible dilution remains the attachment of mathematics education to mathematics that ICMI can guarantee while encouraging cooperative work with other academic fields connected to education" (p. 45). That describes in a very fitting way the framework I was proposing in this talk to reflect on the links, past and future, between mathematics and didactics and between the main communities that support these domains.

Acknowledgments The author wishes to express his gratitude to the colleagues who brought their support in the preparation of this paper, and in particular to his immediate predecessors as ICMI Secretary-General, A. Geoffrey Howson (1983-1990) and Mogens Niss (1991-1998).

Open Access This chapter is distributed under the terms of the Creative Commons Attribution Noncommercial License, which permits any noncommercial use, distribution, and reproduction in any medium, provided the original author(s) and source are credited.

\section{References}

Artigue, M. (2008). ICMI: A century at the interface between mathematics and mathematics education. In M. Menghini, F. Furinghetti, L. Giacardi, \& F. Arzarello (Eds.), The first century of the International Commission on Mathematical Instruction (1908-2008). Reflecting and shaping the world of mathematics education (pp. 185-198). Rome, Italy: Istituto della Enciclopedia Italiana.

Artigue, M. (2010). Penser les relations entre mathématiciens, enseignement des mathématiques, recherche sur et pour cet enseignement: que nous apportent l'expérience des IREM et celle de la CIEM? [Reflecting on the relations between mathematicians, teaching of mathematics, research on and for this teaching: what do the experience of the IREMs and that of ICMI bring us?] Les mathématiciens et l'enseignement de leur discipline en France. [Mathematicians and the teaching of their discipline in France.] Séminaire des IREM et de Repères IREM (March 2010). Unpublished manuscript.

Bass, H. (2008a). Mathematics, mathematicians, and mathematics education. In M. Niss (Ed.), Proceedings of the tenth International Congress on Mathematical Education (pp. 42-55). Roskilde, Denmark: IMFUFA.

Bass, H. (2008b). Moments in the life of ICMI. In M. Menghini, F. Furinghetti, L. Giacardi, \& F. Arzarello (Eds.), The first century of the International Commission on Mathematical Instruction (1908-2008). Reflecting and shaping the world of mathematics education (pp. 924). Rome, Italy: Istituto della Enciclopedia Italiana.

Bass, H., \& Hodgson, B. R. (2004). The International Commission on Mathematical InstructionWhat? Why? For whom? Notices of the American Mathematical Society, 51(6), 639-644. 
Blomhøj, M. (2008). ICMI's challenges and future. In M. Menghini, F. Furinghetti, L. Giacardi, \& F. Arzarello (Eds.), The first century of the International Commission on Mathematical Instruction (1908-2008). Reflecting and shaping the world of mathematics education (pp. 169180). Rome, Italy: Istituto della Enciclopedia Italiana.

Brewster, D. (1819). A treatise on the kaleidoscope. Edinburgh, UK: Archibald Constable \& Co.

Dorier, J.-L. (2008). Reaction to J. Kilpatrick's plenary talk: The development of mathematics education as an academic field. In M. Menghini, F. Furinghetti, L. Giacardi, \& F. Arzarello (Eds.), The first century of the International Commission on Mathematical Instruction (19082008). Reflecting and shaping the world of mathematics education (pp. 40-46). Rome, Italy: Istituto della Enciclopedia Italiana.

Dossey, J. A. (1992). The nature of mathematics: its role and its influence. In: D. A. Grouws (Ed.), Handbook of research on mathematics teaching and learning (pp. 39-48). New York, NY: Macmillan.

Education Committee of the European Mathematical Society. (2011). 'Solid findings' in mathematics education. Newsletter of the European Mathematical Society, 81, 46-48.

Fehr, H. (1920-1921). La Commission internationale de l'enseignement mathématique de 1908 à 1920: Compte rendu sommaire suivi de la liste complète des travaux publiés par la Commission et les Sous-commissions nationales. L'Enseignement Mathématique, s. 1, 21, 305339.

Furinghetti, F. (2003). Mathematical instruction in an international perspective: The contribution of the journal L'Enseignement Mathématique. In D. Coray, F. Furinghetti, H. Gispert, B. R. Hodgson, \& G. Schubring (Eds.), One hundred years of L'Enseignement Mathématique: Moments of mathematics education in the twentieth century (Monographie 39, pp. 19-46). Geneva, Switzerland: L'Enseignement Mathématique.

Furinghetti, F. (2008). Mathematics education in the ICMI perspective. International Journal for the History of Mathematics Education, 3(2), 47-56.

Furinghetti, F., Menghini, M., Arzarello, F., \& Giacardi, L. (2008). ICMI Renaissance: The emergence of new issues in mathematics education. In M. Menghini, F. Furinghetti, L. Giacardi, \& F. Arzarello (Eds.), The first century of the International Commission on Mathematical Instruction (1908-2008). Reflecting and shaping the world of mathematics education (pp. 131-147). Rome, Italy: Istituto della Enciclopedia Italiana.

Graf, K.-D., \& Hodgson, B. R. (1990). Popularizing geometrical concepts: the case of the kaleidoscope. For the Learning of Mathematics, 10(3), 42-50.

Hobson, E. W., \& Love, A. E. H. (1913). Proceedings of the fifth International Congress of Mathematicians. Cambridge, UK: Cambridge University Press.

Hodgson, B. R. (1987). La géométrie du kaléidoscope. Bulletin de l'Association mathématique du Québec, 27(2), 12-24. Reprinted in: Plot (Supplément: Symétrie - dossier pédagogique) 42 (1988), 25-34.

Hodgson, B. R. (2001). The mathematical education of school teachers: role and responsibilities of university mathematicians. In D. Holton (Ed.), The teaching and learning of mathematics at university level: An ICMI study (pp. 501-518). (New ICMI Study Series, No. 7) Dordrecht, The Netherlands: Kluwer.

Hodgson, B. R. (2004). The mathematical education of schoolteachers: a baker's dozen of fertile problems. In J.P. Wang \& B.Y. Xu (Eds.), Trends and challenges in mathematics education (pp. 315-341). Shanghai, China: East China Normal University Press.

Hodgson, B. R. (2008). Some views on ICMI at the dawn of its second century. In M. Menghini, F. Furinghetti, L. Giacardi, \& F. Arzarello (Eds.), The first century of the International Commission on Mathematical Instruction (1908-2008). Reflecting and shaping the world of mathematics education (pp. 199-203). Rome, Italy: Istituto della Enciclopedia Italiana.

Hodgson, B. R. (2009). ICMI in the post-Freudenthal era: Moments in the history of mathematics education from an international perspective. In K. Bjarnadóttir, F. Furinghetti, \& G. Schubring (Eds.), "Dig where you stand": Proceedings of the conference on On-going research in the history of mathematics education (pp. 79-96). Reykjavik: University of Iceland, School of Education. 
Hodgson, B. R. (2011). Collaboration et échanges internationaux en éducation mathématique dans le cadre de la CIEM: Regards selon une perspective canadienne [ICMI as a space for international collaboration and exchange in mathematics education: Some views from a Canadian perspective]. In P. Liljedahl, S. Oesterle, \& D. Allan (Eds.), Proceedings of the 2010 annual meeting of the Canadian Mathematics Education Study Group/Groupe canadien d'étude en didactique des mathématiques (pp. 31-50). Burnaby, Canada: CMESG/GCEDM.

Hodgson, B. R., Rogers, L. F., Lerman, S., \& Lim-Teo, S. K. (2013). International organizations in mathematics education. In M. A. (Ken) Clements, A. Bishop, C. Keitel, J. Kilpatrick, \& F. K. S. Leung (Eds.), Third international handbook of mathematics education (pp. 901-947). New York, NY: Springer.

Howson, A. G. (1984). Seventy-five years of the International Commission on Mathematical Instruction. Educational Studies in Mathematics, 15(1), 75-93.

Kilpatrick, J. (2003). Twenty years of French didactique viewed from the United States. For the Learning of Mathematics, 23(2), 23-27. [Translation of: Vingt ans de didactique française depuis les USA. In M. Artigue, R. Gras, C. Laborde, \& P. Tavignot (Eds.), Vingt ans de didactique des mathématiques en France: Hommage à Guy Brousseau et Gérard Vergnaud (pp. 84-96). Grenoble, France: La Pensée Sauvage, 1994.].

Kilpatrick, J. (2008). The development of mathematics education as an academic field. In M. Menghini, F. Furinghetti, L. Giacardi, \& F. Arzarello (Eds.), The first century of the International Commission on Mathematical Instruction (1908-2008). Reflecting and shaping the world of mathematics education (pp. 25-39). Rome, Italy: Istituto della Enciclopedia Italiana.

Kilpatrick, J. (2012). Lost in translation. Short Proceedings of the "Colloque hommage à Michèle Artigue". Paris: France, Université Paris Diderot - Paris 7. (Accessible at http://www. colloqueartigue2012.fr/).

Klein, F. (1932). Elementary mathematics from an advanced standpoint: Arithmetic, algebra, analysis. New York, NY: Macmillan. [Translation of volume 1 of the three-volume third edition of Elementarmathematik vom höheren Standpunkte aus. Berlin, Germany: J. Springer, 1924-1928.].

Kline, M. (1980). Mathematics: The loss of certainty. New York, NY: Oxford University Press.

Lehto, O. (1998). Mathematics without borders: A history of the International Mathematical Union. New York, NY: Springer.

Lovász, L. (2010). Overview on Union activities. (Section 3.1 of the report of the 16th General Assembly of the International Mathematical Union - IMU) Bulletin of the International Mathematical Union, 59, 10-15.

Mac Lane, S. (1971). Categories for the working mathematician. New York, NY: Springer.

Schubring, G. (2003). L'Enseignement Mathématique and the first international commission (IMUK): The emergence of international communication and cooperation. In D. Coray, F. Furinghetti, H. Gispert, B. R. Hodgson, \& G. Schubring (Eds.), One hundred years of L'Enseignement Mathématique: Moments of mathematics education in the twentieth century (Monographie 39, pp. 47-65). Geneva, Switzerland: L'Enseignement Mathématique.

Schubring, G. (2008). The origins and early incarnations of ICMI. In M. Menghini, F. Furinghetti, L. Giacardi, \& F. Arzarello (Eds.), The first century of the International Commission on Mathematical Instruction (1908-2008). Reflecting and shaping the world of mathematics education (pp. 113-130). Rome, Italy: Istituto della Enciclopedia Italiana.

Sierpinska, A. (1998). Whither mathematics education? In C. Alsina, J. M. Alvarez, M. Niss, A. Pérez, L. Rico, \& A. Sfard (Eds.), Proceedings of the 8th International Congress on Mathematical Education (pp. 21-46). Sevilla, Spain: S.A.E.M. Thales.

Steiner, H. G. (1968). The plans for a Center of didactics of mathematics at the University of Karlsruhe. In N. Teodorescu (Ed.), Colloque international UNESCO "Modernisation de l'enseignement mathématique dans les pays européens”' (pp. 423-435). Bucharest, Romania: Éditions didactiques et pédagogiques.

Winsløw, C. (2007). Didactics of mathematics: an epistemological approach to mathematics education. The Curriculum Journal, 18(4), 523-536. 